\title{
Improve English Teaching Content and Maintain Global Cultural Diversity
}

\author{
Long Ye $\mathrm{e}^{1,2 \text { a }}$ \\ ${ }^{1}$ Macau University of Science and Technology, Macau, 999078, China \\ ${ }^{2}$ Shaoguan University, Shaoguan, 512005, China \\ a bobyeesgu@163.com
}

Keywords: English teaching, Global Cultural, National culture, Culture diversity

\begin{abstract}
In the context of economic and social globalization, learning English is an essential task for non-English speaking countries. However, the inappropriate English teaching content may impact national culture and undermine the global cultural diversity to a certain extent. From this point of view, this paper discusses the concrete paths to improve the content of English teaching and maintain cultural diversity to provide some references for relevant researchers.
\end{abstract}

\section{Introduction}

English is a special language. It was derived from western culture, but it is functioning as a global language. Language learners cannot avoid learning the culture of the language they are learning for better communication in that language. To understand the culture of a nation or a country, it is impossible to bypass the language of this nation or country because culture is an indispensable environment for language and language is meaningful only when we look at language in culture. So it is natural for English learners to acquire information about western culture where English was cultivated. A variety of teaching methods and teaching means are applied in English teaching, and they are aimed at cultivating students' comprehensive ability of using English, especially listening and speaking ability, so that they can communicate effectively in English in the future work and social interactions. Guided with foreign language Theories, college English curriculum requirements in China were specified with English Language rules, practical skills of learning strategies and intercultural communication as the main content [1]. However, on the intercultural communication side, English teaching in China can be easily neglecting Chinese national culture due to its inappropriate distribution of content on culture, which always causes unbalanced intercultural communication. Many English learners in China express western culture items well are aphasic on Chinese national culture in English. In English teaching, the cultural background knowledge of English speaking countries is indispensable. However, as the global language, English should also include contents of national cultures of other countries to contribute to the diversity of global culture. Supplementing Chinese national culture into English teaching in China can make English learning have the great potential to spread Chinese national culture and preserving it into the diversity of global culture.

\section{Impact of Inappropriate English Teaching Content on National Culture}

Language and culture are in a relation of interdependence. As a cultural carrier and communication tool, language will also restrict and influence the spread of culture. Therefore, culture cannot exist without language. With the development of economy, the progress of science and technology and the deepening of communication between countries, the culture is also advancing with the times, and new language and language expressions will also emerge. This is the side that culture promotes and restricts language. Contrarily, people cannot communicate with a language 
efficiently without knowledge of the culture it carries. Many English words and phrases are the product of a culture. Without understanding the cultural background of a language, it is impossible to really understand the language. Therefore, in the process of English learning, it is important to understand the customs and culture of English speaking countries. Their unique national characteristics and cultural traditions, and social customs and lifestyles are indispensable for understanding the language. English teaching in China emphasizes a lot on culture contents of western countries to avoid pragmatic errors caused by the lack of cultural knowledge in English speaking countries, whereas, the neglect of expressions on items of Chinese national culture will cause an unbalanced intercultural communication. When Chinese English learners communicate with foreigners, they always avoid their national culture content for not being able to express items related in English. However, those foreigners are most willing to know more about Chinese traditional culture rather than talking about themselves or culture content of their nations. Therefore, a unidirectional communication mode would be formed through this way, which is unpleasant consequence for both parties of the communication and is harmful for a win-win intercultural communication. Worst of all, if all nonnative speakers of English communicate with native ones unidirectionally like this, the global culture transmitted by the global language, English, would be at risk of becoming culture of English speaking countries. Eastern and Western countries have contributed to the diversity of world culture. Cultural diversity promotes world harmony [2]. Therefore, we should respect and safeguard cultural diversity, promote equal dialogue among civilizations, and jointly develop and prosper together.

\section{Improve English Teaching Content to Maintain Global Cultural Diversity}

Emphasize National Consciousness. The process of globalization has made the countries of the world more closely linked, and the flow of people has become more frequent. This seems to me to you, as the situation is bound to cause people's illusion. It dilutes the concept of state sovereignty, and weakens the people's recognition of the national culture [3]. On the other hand, the competition between countries is still complex and fierce, and the nation-state is still the main body of international relations. Therefore, English teaching needs to deal with the challenges posed by the concept of national state from the background of globalization, pay attention to the safety of national culture and enhance national awareness. Although the United States attempts to carry out cultural hegemonies and influence heterogeneous culture, the national culture formed by the long historical accumulation will not be swallowed up by the strong culture because of its inherent cultural characteristics. Chinese culture has a long history, and the philosophy and thinking philosophy contained in it deserve world reference. How to spread Chinese culture to the world is a historical task that contemporary college students should shoulder. After the Opium War, China had a history of humiliation and backwardness. At the beginning of the reform and opening, China's backward production technology forced us to follow the west. The status of English was once higher than that of Chinese in China, and most college English teachers received English education in the age of inequality between Chinese and Western cultures. Therefore, College English teachers often have a solid foundation of English language, familiar with western culture, but their Chinese cultural consciousness is not high, and they lack competence of communicating on Chinese national culture in English. If the College English teachers do not change their beliefs about Chinese culture and change the teaching of Chinese culture into a conscious teaching action, it will be difficult to reverse the uneven position of Chinese and Western cultures in College English classes.

Reform Teaching Materials. Our English textbooks show great respect for western culture, but we need the public, especially the western countries, to enhance their understanding, recognition and respect for Chinese culture. To strengthen the ability of language learners to express their own national culture in foreign languages is very helpful in disseminating Chinese culture and promoting mutual respect as materials in English are more likely to have greater impact than those in most other languages and they are more needed [4]. Six years of primary and middle school English learning has enabled students to understand the customs and ways of life in English speaking countries. Therefore, 
after the indispensable western culture infiltration is almost finished, we should gradually use more Chinese culture related teaching materials in high school and college English education. In addition, various schools can also write English textbooks combining Chinese culture and local culture according to the characteristics of their own schools. They can be used as self-study or self-reading materials for students. The innovation of English teaching begins with the updating of teaching materials and teaching ideas. Language teaching is the first step in English teaching, and the introduction of Chinese culture should be a contributing factor in the achievement of English language teaching. Language is the carrier of culture and the reflection of culture. Therefore, the teaching of English should be based on language teaching and supplemented by cultural teaching. We do not prevent the introduction of Chinese culture from the most active part of language. In the era of cultural globalization, the impact of foreign culture on Chinese culture is inevitable [3]. Any kind of culture and cultural exchange, it can rest on its laurels. In the process, we should pay attention to the consciousness of national cultural protection [3]. Besides original English articles, we can also translate excellent Chinese articles on Chinese culture as teaching materials. Teaching materials can be made by asking professionals of Chinese culture prepare some special contents and translate them into English as well. Through the infiltration of Chinese culture in the teaching material, the local cultural consciousness of the intercultural communication subject should be defined and the internationalized talents with comprehensive cultural quality should be cultivated.

Optimize English Test. Examinations are still one of the main means for us to promote students' study. Many language learners judge their language proficiency by using popular tests even though they are not exam-oriented. So, proficiency tests such as College English Test (CET) or achievement tests such as final exams can always have a strong influence on students 'learning. CET in China acts as a conductor in college English practical teaching. To value the importance of expressing Chinese culture in English and promote Chinese culture, it did a reform on its translation part by replacing the former translation of sentences with paragraph translation and integrating Chinese culture into the paragraph translation. The translation of sentences in CET before the reform test the students' vocabulary and grammatical knowledge. After the reform of the paragraph translation, the students' comprehensive abilities to use English translation of the content is to Chinese cultural, economic and social development and other topics are tested. This is the first time to join Chinese cultural elements in the exam. It is a good start for optimizing English test with due respect of Chinese national culture. However, the test of Chinese culture should not be limited to paragraph translation in CET. To promote the fusion of perfect English teaching and cultural education, it can also be infiltrated in other parts of CET such as reading and listening and other tests besides CET.

Broaden Infiltration Channels. College English teachers should stimulate their students' interest in Chinese culture by developing colorful extracurricular activities to improve their ability of expression on Chinese culture. Extracurricular activities can help students acquire knowledge in various ways and ways in a relaxed and equal atmosphere. It is not only an effective complement to classroom teaching, but also an important and special way to infiltrate Chinese culture. Teachers can also organize students to broaden their learning channels and improve their cultural accomplishment through colorful extracurricular activities, such as performing, watching movies, grouping discussions and adapting plays. Movies and music could the best embodiments of a nation and a country's culture, and movies. Wonderful plots from movies and, a piece of beautiful melody from a song will let students fascinated and can stimulate students' interest in learning, naturally improving students listening and speaking abilities. It would be meaningful and attractive if we provide some documentaries or movies of Chinese culture or analyze Chinese music in English for the process of English teaching. In English extracurricular activities, students can understand the customs and culture of Britain and the United States through their favorite channels, which also works for Chinese culture. Many Chinese culture contents such as tea ceremony, paper cutting, calligraphy and martial arts are best suitable for colorful activities and can easily constitute a pleasant learning experience. There are many books on this subject in the school library and reading room. Many universities have specialized foreign language reading room and electronic reading room, the students there can dabble in browsing, watch movies and listen to English songs. Those facilities can also be used for Chinese 
culture part by modifying the contents used. English corners could use topics related to Chinese culture and can make better intercultural communication when English native speakers are involved.

\section{To Enhance Cross-Culture Communication Competence is an Essential Means to Improve English Teaching Content}

Cultural education is an important part of College English education, and it is also an important aspect of improving students' intercultural communicative competence, which puts forward higher requirements for College English teachers [5]. The quality of intercultural communication among English teachers undoubtedly plays an important role in College English teaching. College English teacher should assume the responsibility entrusted to us by the times, do in-depth study of the essence of the Chinese and foreign culture, widely hunt fresh cultural phenomenon, bravely explore the essence of culture, expand the research field of culture and actively devote to the cause of culture infiltration in English teaching. Only by constantly laying a solid foundation of their own language, improving their cultural accomplishment and improving their intercultural communicative competence can they cultivate qualified students of excellent intercultural communication competence and become the mainstay of cultural exchanges and cooperation between China and foreign countries. Besides the covering of culture background of English native speaking countries, college English teachers should also enhance their cultural awareness, actively learn Chinese culture, and their national cultural self-confidence. It is necessary for them to highlight the cultural consciousness of the communication subject with the spirit of equality and tolerance to cultural differences, and a dialectical view of advantages and disadvantages of Chinese and Western culture [6]. If good cross-cultural communication platforms can be provided by college English teaching, foreign language talents in the new period of training with Chinese and Western culture can spread Chinese culture in English, and for English teachers in China, they are both language professors and cultural inheritors. Therefore, it is crucial for English teachers to have a strong sense of native culture, actively cultivate their own native culture and consciously compare Eastern and Western culture to make the students' cross-cultural communicative ability training to the maximum extent.

\section{Conclusion}

English, as an important medium of Chinese cultural output, can effectively disseminate Chinese culture. Introducing Chinese national culture into English teaching to improve English teaching content can enhance students' awareness of learning Chinese cultural and the ability of cross-cultural communication. English teachers should transmit the national culture to the world factually and comprehensively to maintain the cultural diversity of the world.

\section{References}

[1] Wei Yuju. A Survey of Consciousness of Synchronous Chinese and English Culture in College English Teaching [D]. Guangxi Normal University, 2014.

[2] Chen Fangrong. On Cultural Diversity and the Chinese-English Translation of China's Intangible Cultural Heritage [J]. Journal of Zhejiang Normal University (Social Sciences), 2013, 38(3): 64-69.

[3] Chen Ying. The Spread of English in a Globalised World-A Discussion on its Adverse Effecton Language Diversity and Cultural Identity [J]. Journal of Language and Literature Studies, 2010(11): 81-82+132.

[4] Marie H. Roesgaard. Global Citizenship Education: A Biased Field [J]. Foreign Languages Research, 2016(6): 49-54.

[5] Hua Li, Foreign Language Talent Training Mode under Network Based on Mutiple Intelligence Theory [C]. MSE 2011-10-01

[6] Zhao Shiju, Chen Si. National Language Capacity in Global Competition [J]. Social Sciences in China, 2016(3): 93-110. 